\title{
Computational Investigation of Base Drag Reduction for a Projectile at Different Flight Regimes
}

\author{
M. A. Suliman*, O. K. Mahmoud ${ }^{* *}$, M. A. Al-Sanabawy ${ }^{* *}$, O. E. Abdel-Hamid ${ }^{* *}$
}

\begin{abstract}
A computational investigation for the $155 \mathrm{~mm}$ artillery shell was conducted for the purpose of reducing the base drag. Three case studies were conducted to investigate the properties of the flow field around the shell for the flight at different Mach numbers at zero angle of attack. The three cases were: a shell with boattail, a shell with base cavity and a shell with base bleed. Also, combinations of these three cases were investigated. The higher drag reduction was demonstrated when using a combination of the three effects. For this latter case it was possible to realize a drag coefficient reduction of $\sim 60 \%$ at subsonic regime and $\sim 20$ $30 \%$ at transonic and supersonic regimes. Based on the present methodology, a design optimization for minimum drag can be applied on similar flying bodies.
\end{abstract}

Keywords: Aerodynamics, computational fluid dynamics, base drag, projectile, boattail, base cavity, base bleed.

\section{Introduction:}

One of the most important aerodynamic performance characteristics for the projectile's shell is the total drag. The total drag for projectiles can be divided into three components: (i) pressure drag (excluding the base), (ii) viscous (skin friction) drag, and (iii) base drag [1]. The base drag is a major contributor to the total drag, particularly at transonic speeds. Thus, the determination and minimization of base drag is essential in minimizing the total drag of projectiles. The breakdown of the total drag into various components is important in the preliminary design stage of a shell. This Information can aid the designer to find potential areas for drag reduction and achieve a desired increase in range and/or terminal velocity of projectiles since they are affected by the projectile drag.

Within the field of artillery techniques there has been a continual striving to increase the range and precision of field guns. Increased range is achieved either by gun improvements, which even include modifications to propellant charges such that redesign of gun parts is required due to for example increased gas pressure in the barrel, or by improvements in the projectile performance. Improved projectile performance can be achieved in several different ways which to a certain extent can be combined in one and the same projectile. Base drag contributes generally to a relatively large part of the total drag and depends upon the fact that the base pressure due to the resulting wake flow in the base region is lower than the ambient air pressure.

\footnotetext{
*Ph. D Student, Kararry University, Khartoum, Sudan, mutwkil@ hotmail.com

Egyptian Armed Forces, MTC.
} 
For axisymmetric aerodynamic bodies in supersonic flight, the flow field in the wake region has a considerable effect on the aerodynamic drag. Even small changes in the flow behavior of the wake may affect the performance of the entire flight vehicle, e.g., missiles, rockets, or projectiles. Flight tests with common projectiles have shown that the base drag may account for up to $35 \%$ of the total drag [2]. Base drag, arising from flow separation at the blunt base of a body, can be a sizeable fraction of total drag in the context of projectiles, missiles and afterbodies of fighter aircraft; for example, the base drag component can be as high as $50 \%$ of the total drag for a missile with power off. [3]

\section{Factors Affecting Base Drag}

Base drag is influenced by a variety of flow and geometrical parameters. With turbulent boundary layer ahead of the base, and in the absence of jet flow, the major factors include: (i) Mach number in the free stream, just ahead of the base; (ii) boundary layer momentum thickness ahead of the base; (iii) base diameter; (iv) angle of attack; (v) afterbody shape (boattail or flare angle, forebody diameter, afterbody length); and (vi) parameters characterizing the base drag reduction device. [4].

\section{Method of Solution}

There are roughly four classes of techniques to predict aerodynamic forces and moments on a projectile in atmospheric flight: empirical methods, wind tunnel testing, computational fluid dynamics simulation, and spark range testing. In computational fluid dynamics (CFD) simulation, the fundamental fluid dynamic equations are numerically solved for a specific configuration. The most sophisticated computer codes are capable of unsteady time accurate computations using the Navier-Stokes equations. Examples of these tools include, for example, CFD++, Fluent, and Overflow-D [5]. The ability to compute the base region flow field for projectile configurations using Navier-Stokes computational techniques has been developed over the past few years. This capability is very important for determining aerodynamic coefficient data, including the total aerodynamic drag [6].

The $155 \mathrm{~mm}$ artillery shell is widely used in army applications. It is available in many different configurations, for example, $155 \mathrm{~mm}$ M107 and 155mm M2000, shown in Fig. 1. The geometric parameters of $155 \mathrm{~mm}$ afterbody is illustrated in Fig. 2.
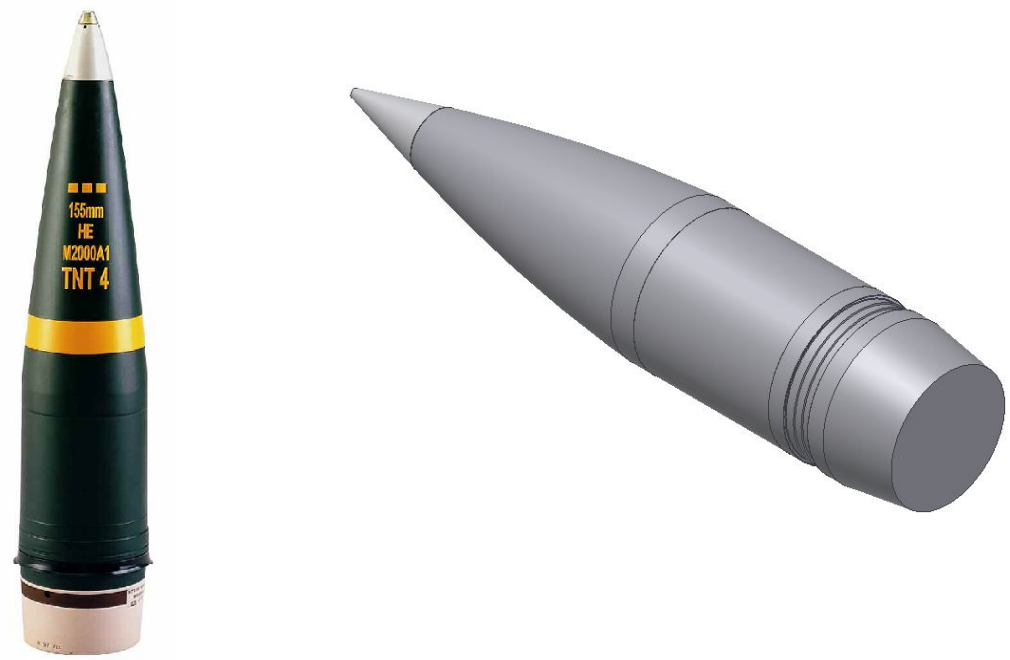

Fig. 1 155mm M2000 (left), and 155mm M107 (right). 




Fig. 2 Geometric parameters of the projectile afterbody with boattail, base bleed, and base cavity.

Solution was done by using two dimensional axisymmetric pressure based solver with Splart Allmaras viscous model, the pressure and velocity equations have been solved coupled and implicit using second order discretization. The wall $\mathrm{Y}+$ values were maintained in the range of (30-60) for most cases. The solution accuracy depend on stopping iterations if there is no change in drag coefficient up to $5^{\text {th }}$ digit within more than 500 iterations

A computational fluid dynamic package which solves Navier-Stokes equations was used in this work. A computational domain of about 50,000 cells structured mesh was constructed around the model using pressure far field boundary condition as shown in Fig. 3 has been used for the solution. 260 cells was distributed around the body (125 on nose, 65 on cylindrical body and 70 on base), with about 90 cells in the upstream and parallel direction of the model length direction and 130 cells in downstream.

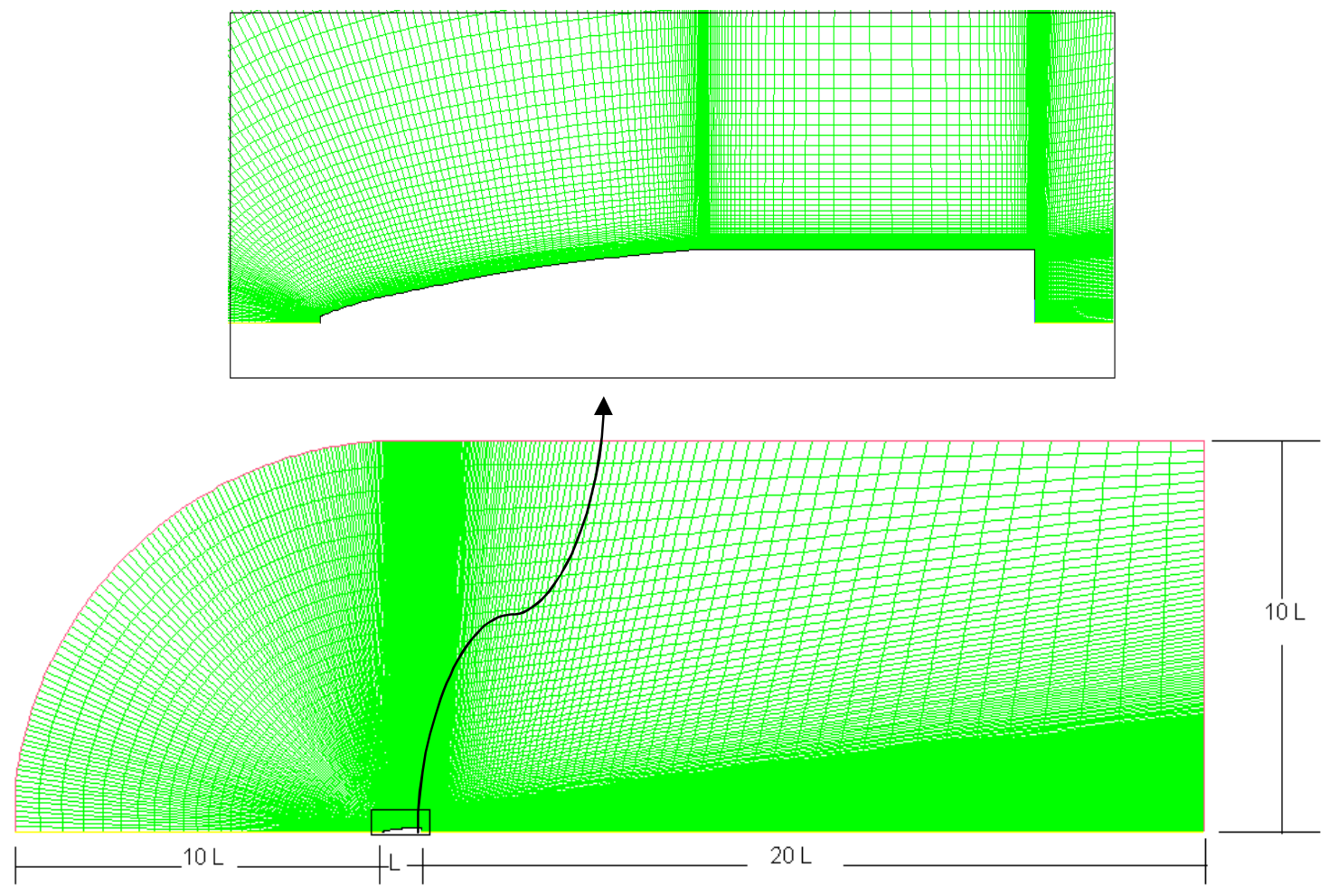

Fig. 3 Computational model of $155 \mathrm{~mm}$ projectile 
In this study we start with a configuration of $155 \mathrm{~mm}$ caliber shell with circular cylinder afterbody and solid flat base referred to as basic configuration. It is a 155mm M549 without boattail (see Fig. 4). This configuration is classified as a highly drag projectile, then we try to minimize its total drag through reducing the base drag by applying three methods of base drag reduction individually, combination of each pair, and then the effect of the three together in one configuration; they are:

1. Boattailing.

2. Base cavity and

3. Base Bleed.

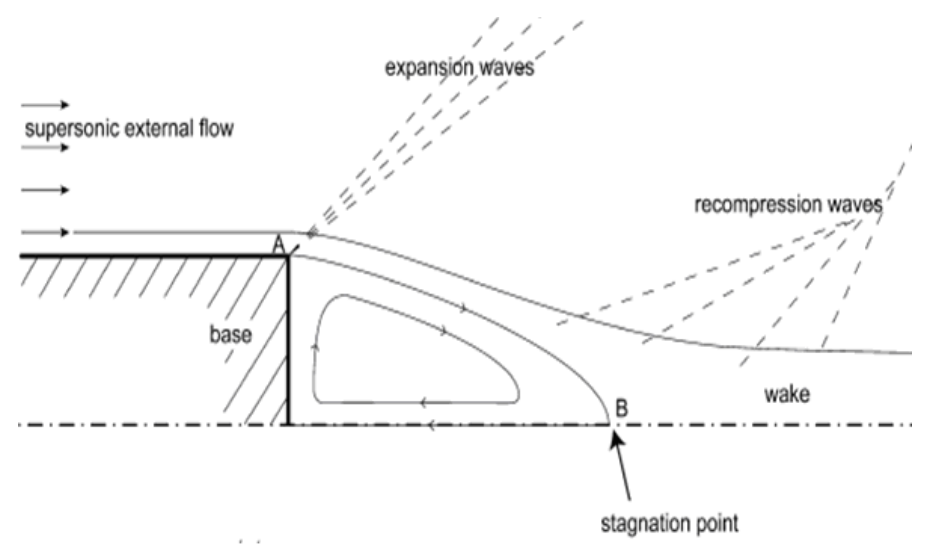

Fig. 4.a Stream lines over circular cylinder afterbody [11]



Fig. 4.b Stream lines over circular cylinder afterbody (basic configuration)

In order to have confidence in the results, the application of the computational code Fluent should be checked against available theoretical or experimental data, if it is possible. Unfortunately, very few experimental results exist for flow field quantities especially in supersonic flow. This is partially due to the difficulty in measuring turbulent quantities in compressible flow, and the difficulty in truly understanding what is being measured. Reference [14] published experimental and theoretical (using a computer program called SANDRAG for U. S. government) results of $C_{D}$ for a typical $155 \mathrm{~mm}$ M549 at M=0.46 they are 0.118 and 0.126 respectively for a similar case fluent output is 0.129 which is a good result. Once the application of the code is validated, the computational optimization will be run in order to determine the optimum shape for minimizing overall drag. 


\section{Boattailing}

The boattail is characterized by two parameters, which are boattail length $\left(\mathrm{L}_{\mathrm{bt}}\right)$ and boattail angle $\left(\theta_{\mathrm{bt}}\right)$, Fig. 2. The boattail length will not be considered as a design variable since experiments have shown that body drag decreases approximately linearly with increasing the boattail length. [7]. The effect of boattailing is well covered in an earlier review which presents evidence that conical boattails are superior to other shapes (ogival, concave) and that appreciable reduction in base drag can be obtained with boat tails of moderate angles and lengths up to about 1 or 1.5 calibers [8]. An optimum boattail configuration results from balancing the increase in wave drag with the reduction of base drag [9]. Using boattail is intended to reduce the vortex area behind the base, Fig. 5, so the strong vortex will be replaced by a smaller and a weaker one, and the low pressure will increase.

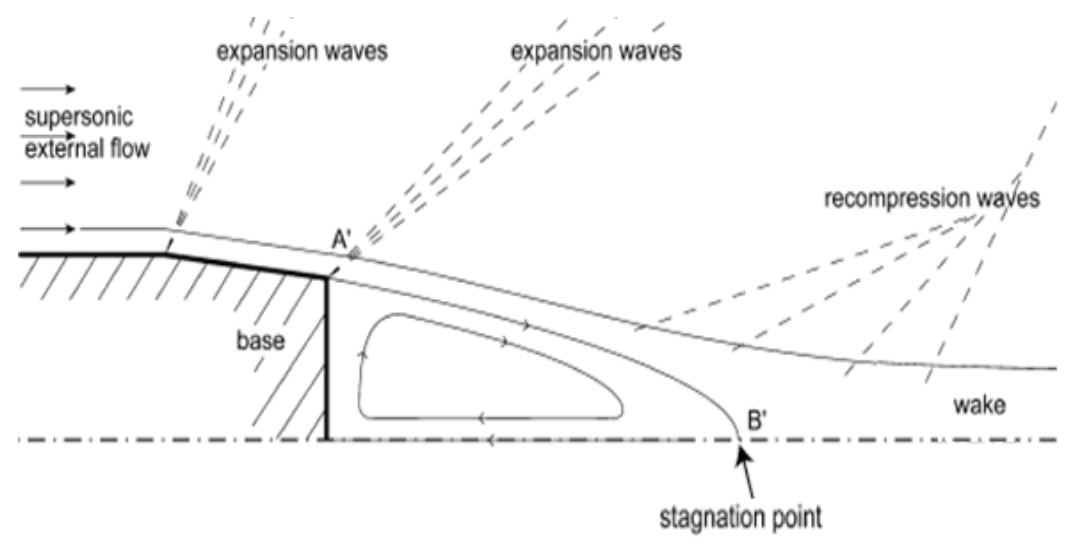

Fig. 5.a Streamlines over a boattailed afterbody [11]

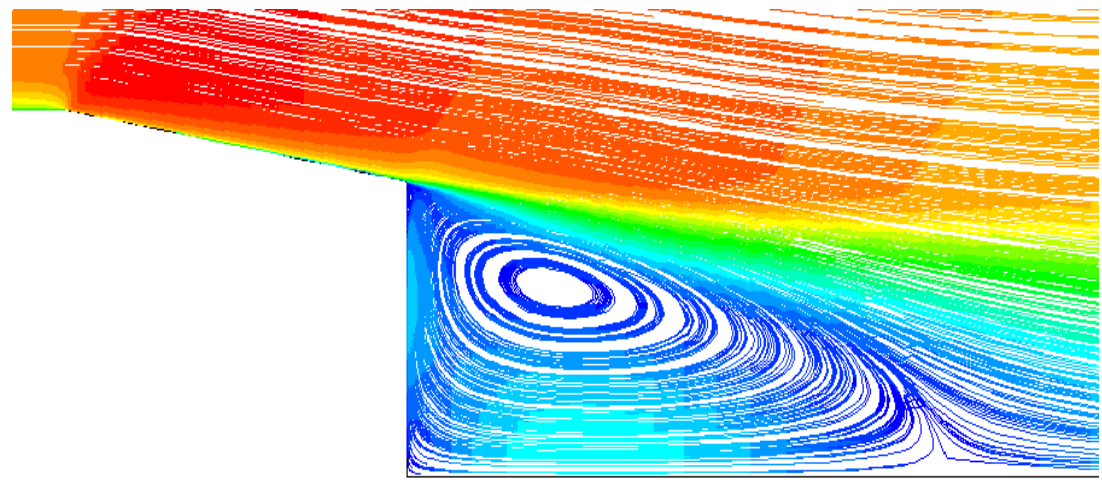

Fig. 5.b Streamlines over a boattailed afterbody

As we increase the boattail angle $\theta_{b t}$ the drag coefficient $C_{D}$ will be decreased until a certain optimum value after which $\mathrm{C}_{\mathrm{D}}$ will increase with $\theta_{\mathrm{bt}}$, . The optimum value of $\theta_{\mathrm{bt}}$ can be between $7.5^{\circ}$ and $10^{\circ}$ for supersonic flow ( $9.5^{\circ}$ for $\mathrm{M}=1.6$ ), which is a good result compared with results of reference [15], and between $14^{\circ}$ and $16^{\circ}$ for subsonic flow ( $15^{\circ}$ for $M=0.7$ ) as shown in Fig. 6 . 




Fig. 6.a Effect of boattail angle on drag coefficient [15]

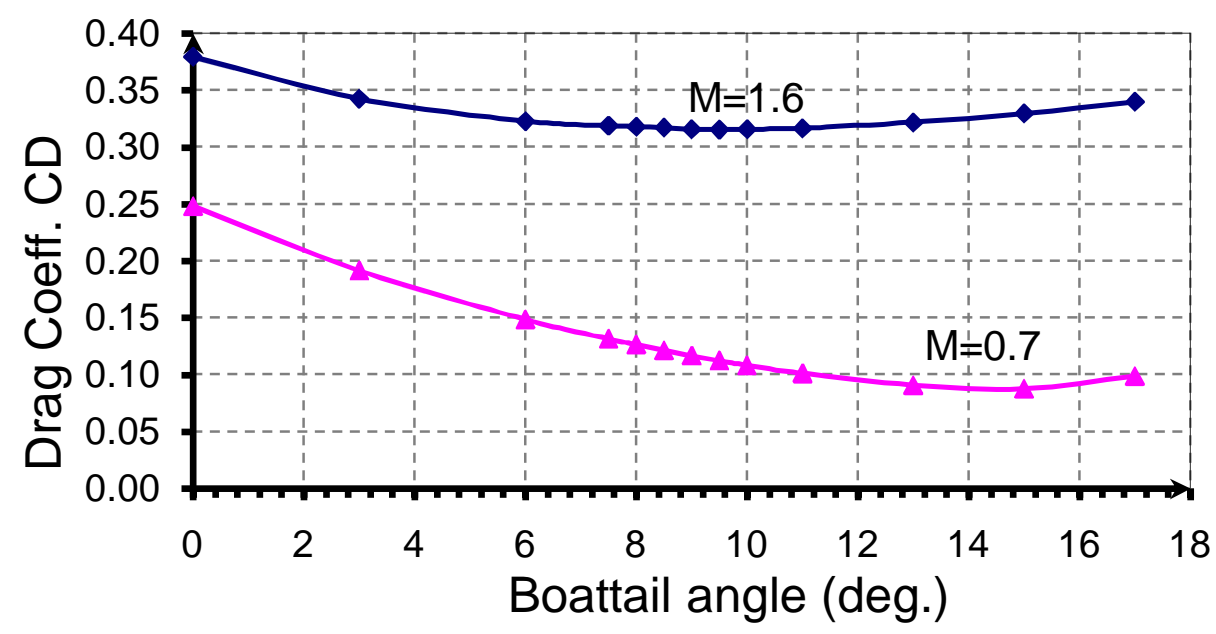

Fig. 6.b Effect of boattail angle on drag coefficient for a $155 \mathrm{~mm}$ projectile

Figure 7 shows that using boattail will reduce the drag coefficient by about $55 \%$ in the subsonic and transonic parts, and by about $12 \%$ in the supersonic part. It must be known that the reduction of drag coefficient in the supersonic part, especially in the first few seconds is very important in increasing the projectile total range.

\section{Base Bleed}

The artillery projectile range is increase by decreasing the aerodynamic drag via ejecting hot gas from the base of the projectile. In order to do that, some propellant and a burning chamber are needed attached to the base; the facility is called the base-bleed unit. The ejected gaseous used to destroy the strong vortex adjacent to the base into more than one weak and small vortices Fig. 8. The out-bled mass flow is estimated to last only the first few kilometers of the flight. However, the first kilometers are the most important from the point of view of extended range [10]. For the injection mass flow rate, the dimensionless injection parameter I is generally used. It defined as the bleed mass flow rate normalized by the product of the base area and the free stream mass flux [11]. 


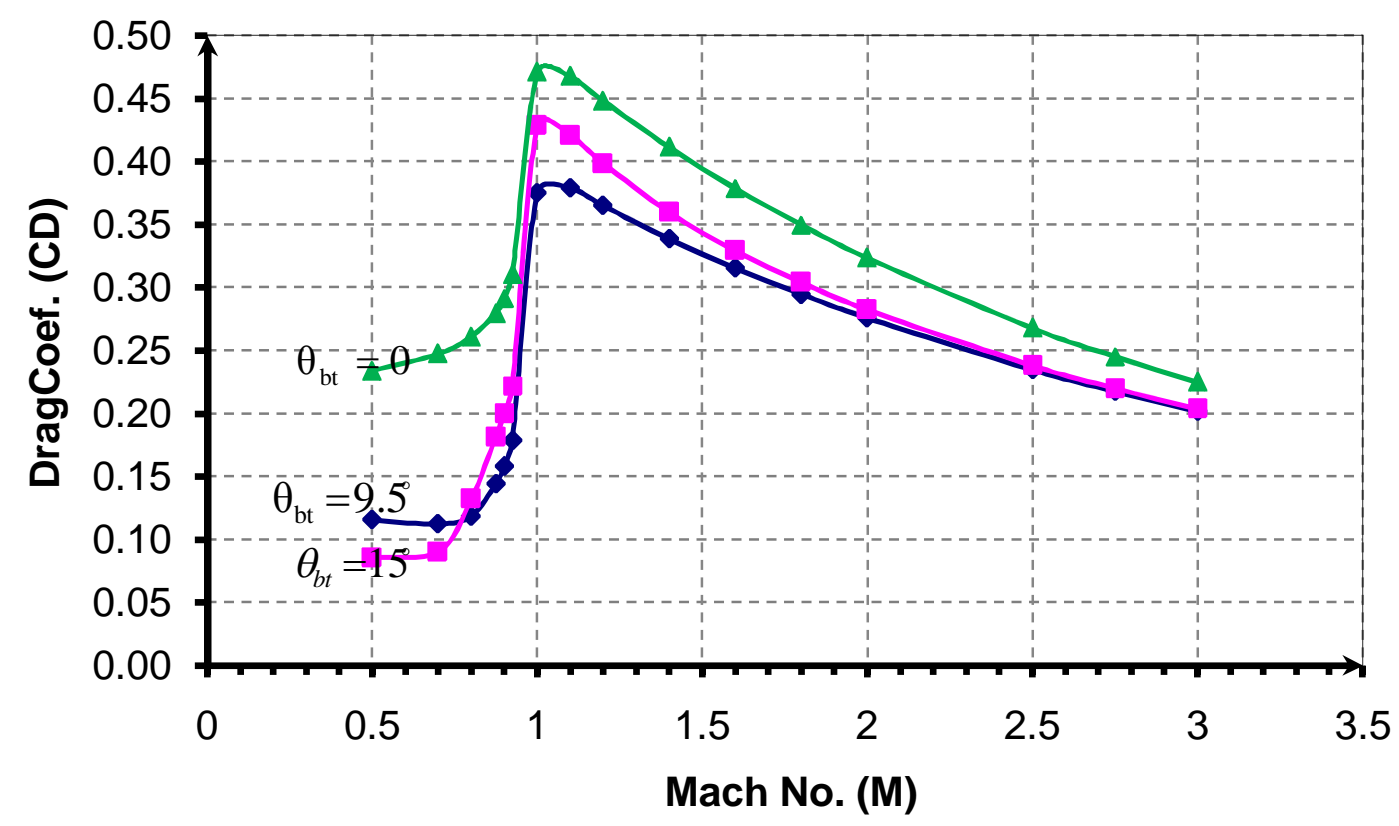

Fig. 7 Effect of boattailing on drag coefficient for a $155 \mathrm{~mm}$ projectile at different fight regimes

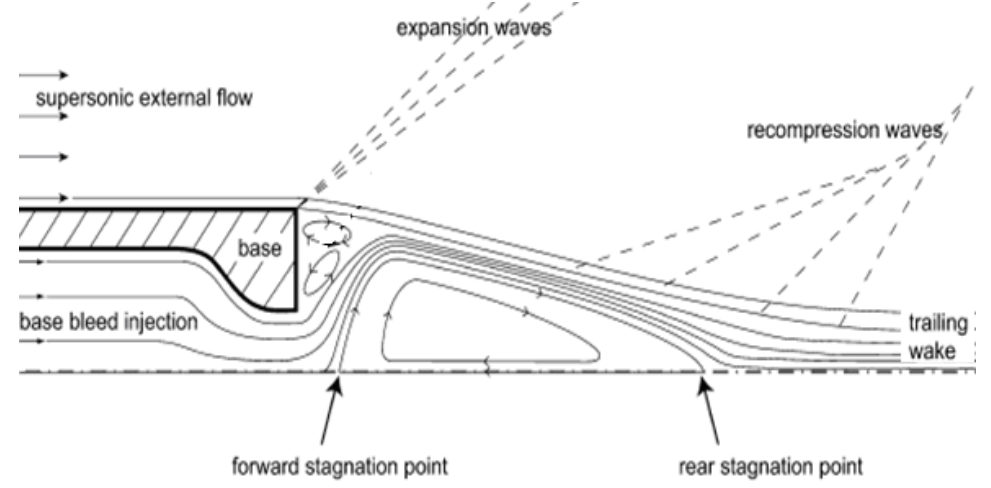

Fig. 8.a Stream lines over afterbody with base bleed [11]

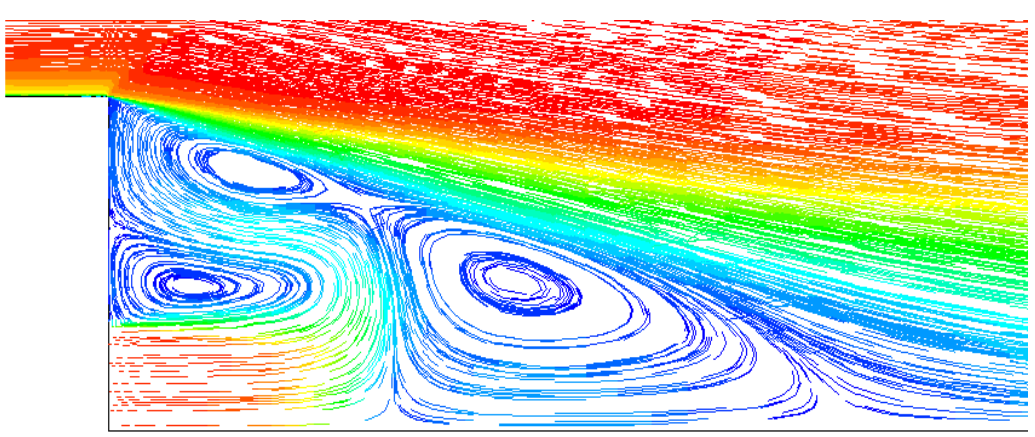

Fig. 8.b Stream lines over afterbody with base bleed (Fluent) 


$$
I=\frac{m}{\rho_{\infty} U_{\infty} A_{\text {base }}}
$$

where: $m$ is propellant mass flow rate, $\rho_{\infty}$ and $U_{\infty}$ are the free stream density and velocity respectively, and $\mathrm{A}_{\text {base }}$ is the base area Fig. 2.

Figure 9 shows that as we increase the mass flow rate of bleeded gaseous drag coefficient will decrease until a certain optimum value of $\mathbf{I}$ which is different for subsonic and supersonic regimes. Results shows that this optimum values are $\dot{\mathrm{m}}=0.073 \mathrm{~kg} / \mathrm{s}, \mathbf{I}=0.0136$ for $\mathrm{M}=0.7$ and $\mathrm{m}=0.09 \mathrm{~kg} / \mathrm{s}, \mathbf{I}=0.0073$ for $\mathrm{M}=1.6$ when there is no boattail. Also this values will be $\dot{\mathrm{m}}=0.0459 \mathrm{~kg} / \mathrm{s}, \mathrm{I}=0.0118$ for $\mathrm{M}=0.7$ and $\dot{\mathrm{m}}=0.095 \mathrm{~kg} / \mathrm{s}, \mathrm{I}=0.0107$ for boattail angle $\theta_{\mathrm{bt}}=9.5^{\circ}$.



Fig. 9.a Effect of mass flow rate on drag coefficient for a $155 \mathrm{~mm}$ projectile (basic configuration)



Fig. 9.b Effect of mass flow rate on drag coefficient for a $155 \mathrm{~mm}$ projectile with boattail angle $=9.5$ 
Figure 10 shows the effect of base bleed of $\mathrm{m}=0.037 \mathrm{~kg} / \mathrm{s}$ with different Mach numbers. It shows that there is a reduction of about $13 \%$ in drag coefficient in both of the subsonic and the supersonic parts.

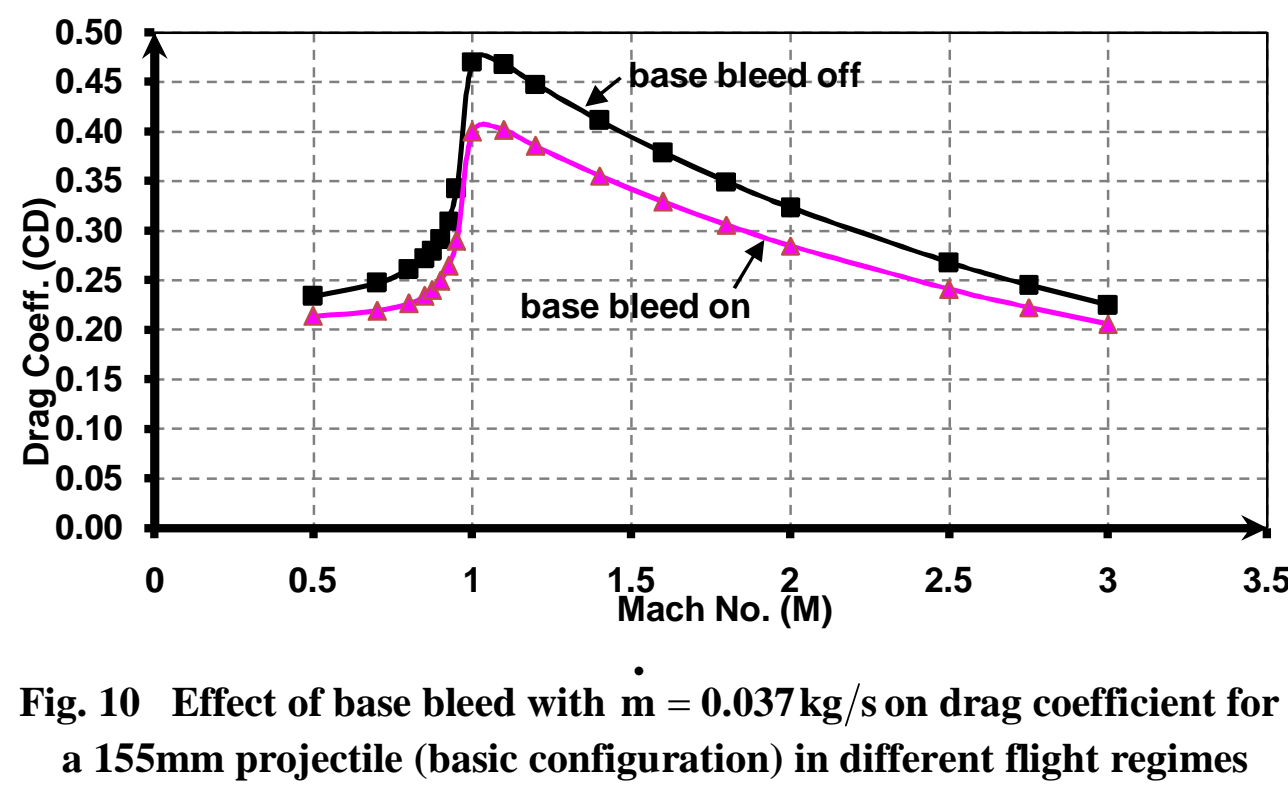

\section{Base cavity}

Several techniques are available for affecting an increase in base pressure by changes in base geometry in the context of two-dimensional subsonic base flows; these include, for example, wake splitter plates, base cavities with and without ventilation and trailing edge serrations. Morel demonstrated the potential benefits of cavities in axisymmetric base flows at low speeds [2]. It is known from several investigations that a base cavity can increase the base pressure and thus decrease the base drag in axisymmetric flow [12]. One must be careful in analyzing bodies with base cavities because of potential for significant contributions to the pitch-plane aerodynamics due to these regions. Limited experimental evidence indicates that the base cavity will produce a stabilizing effect and will cause predictions which ignore this effect to be conservative [13]. Base cavity is defined by two geometric parameters which are cavity depth (H) and cavity lip (t), Fig. 2.

Results shows that the effect of non ventilated base cavity in the drag coefficient is very small compared with boattail and base bleed, it is in the range of about (1-2\%). It is very difficult to determine the optimum cavity shape since it is affected by two variables $(\mathrm{H} \& \mathrm{t})$, and its sensitivity to the free stream velocity. Figure 11 shows the case of no boattail for $t / D=0,075$, and $\mathrm{M}=0.7$, it is clear that drag coefficient decrease linearly as the cavity depth $(\mathrm{H})$ increase until an optimum value (H/D 0.03) after which $C D$ decrease with increasing of $H$, and that is may be referred to increasing in viscose drag. Figure 12 illustrates the effect of cavity lip thickness $(t)$ for a constant cavity depth $(H)(H / D=0.02)$ for $M=0.8$ and $M=1.6$, it is clear that effect of lip thickness is very small compared with that of the depth.

The effect of mass flow rate on drag coefficient at different flight regimes is shown in Figs. 13 and 14 while the stream lines on after body with boattail, base cavity and base bleed are shown in Fig. 15. The reduction in drag coefficient by using a combination of boattail, base cavity and base bleed at different flight regime is well demonstrated in Fig. 16. 




Fig. 11 Effect of base cavity depth on drag coefficient for a $155 \mathrm{~mm}$ projectile without boattail at $M=0.7$


Fig. 12 Effect of lip thickness on drag coefficient for a boattail angle $\theta_{b t}=9.5^{\circ}$ and cavity depth $\mathrm{H} / \mathrm{D}=\mathbf{0 . 0 2}$

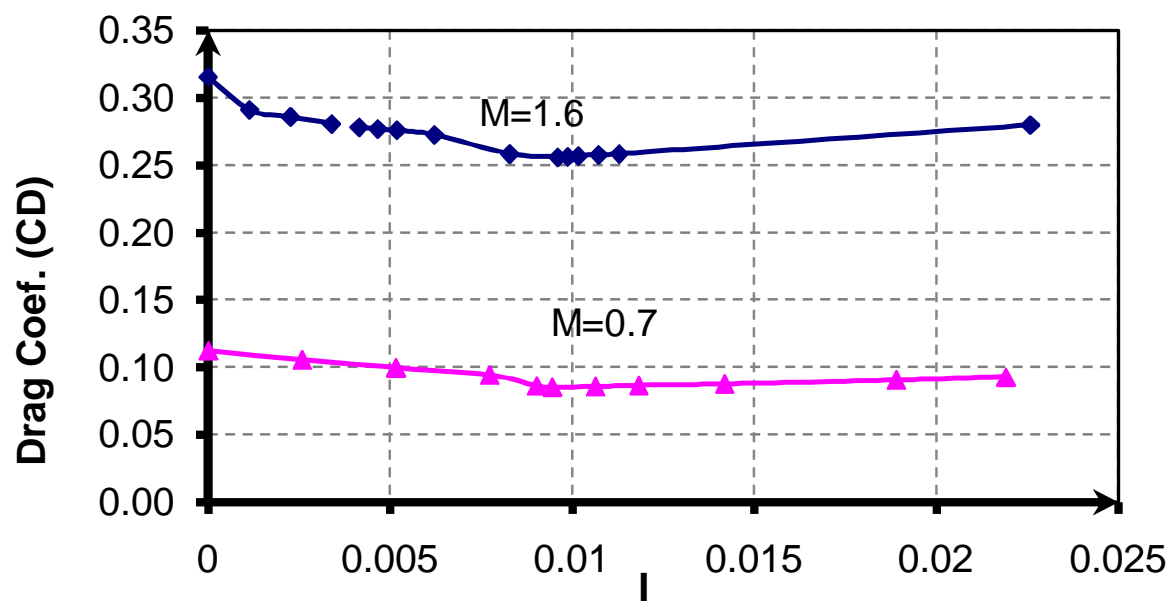

Fig. 13 Effect of mass flow rate on drag coefficient for a $155 \mathrm{~mm}$ projectile with boattail angle $\theta_{b t}=9.5^{\circ}$ and a cavity of $H / D=0.02$ and $t / D=0.2$ 


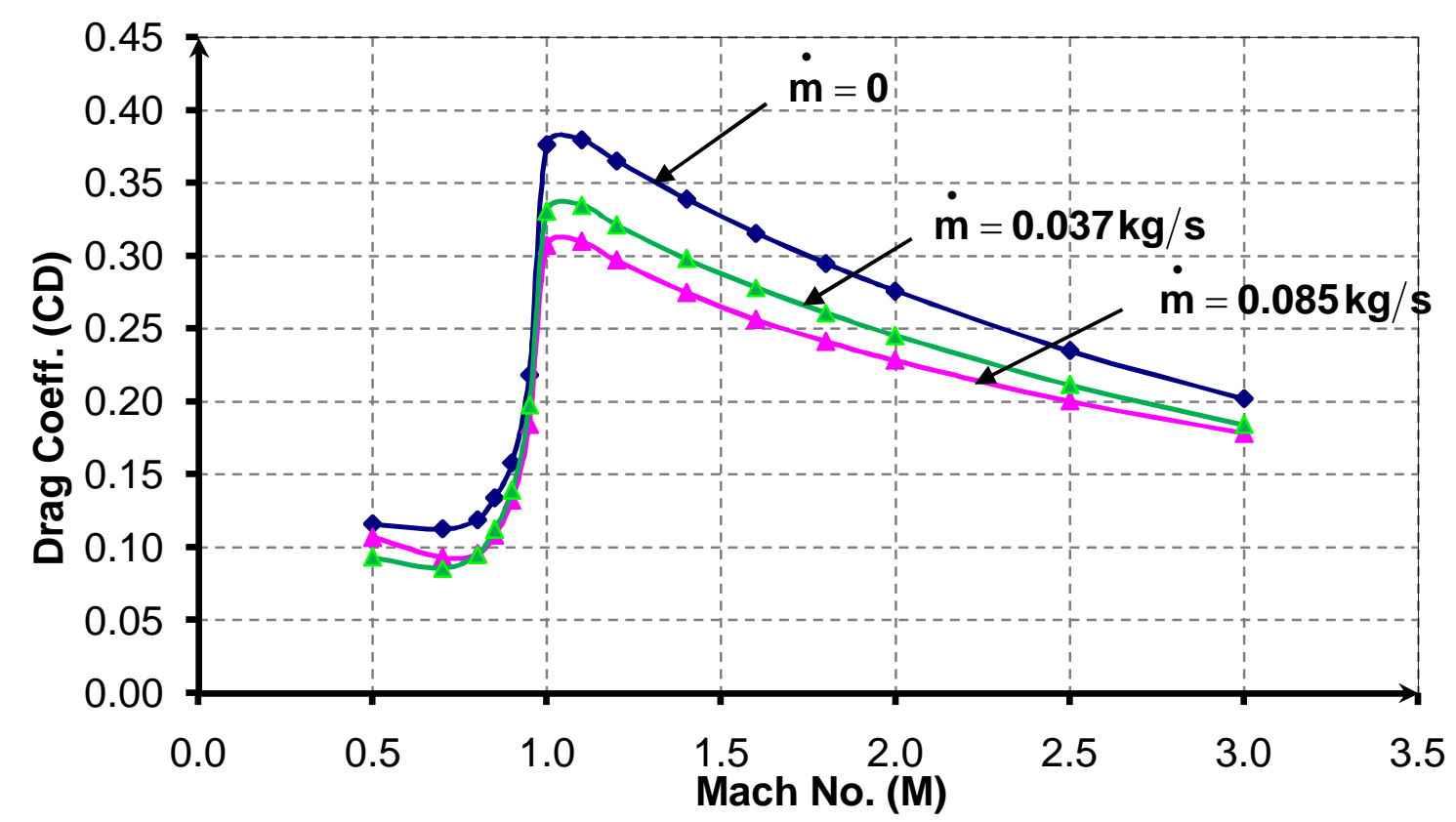

Fig. 14 Effect of mass flow rate on drag coefficient for a $155 \mathrm{~mm}$ projectile with boattail angle $\boldsymbol{\theta}_{\mathrm{bt}}=9.5^{\circ}$ and a cavity of $\mathrm{H} / \mathrm{D}=\mathbf{0 . 0 2}$ and $\mathrm{t} / \mathrm{D}=\mathbf{0 . 2}$ at different flight regimes

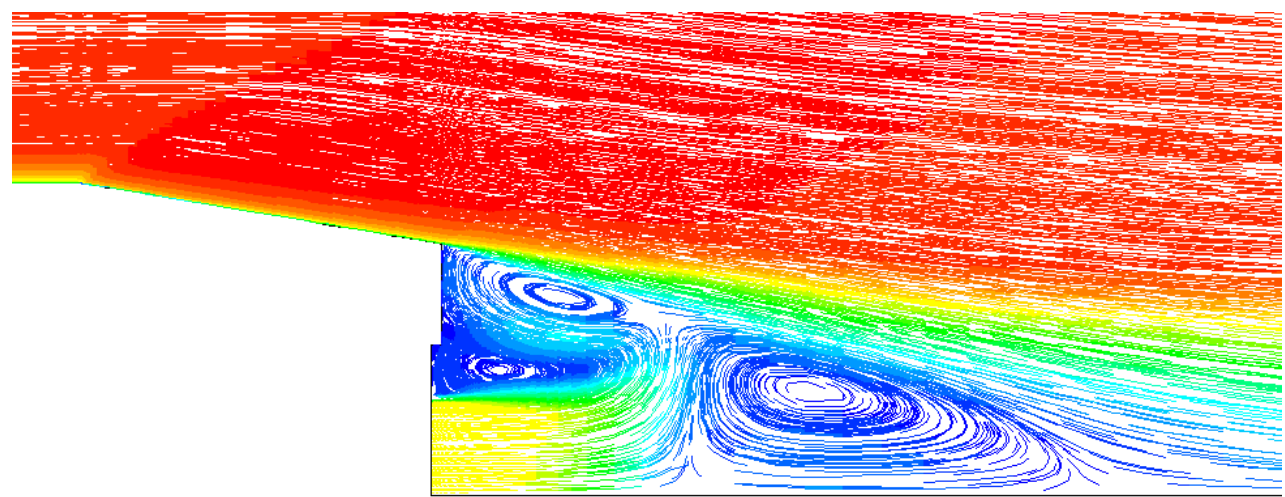

Fig. 15 Stream lines on after body with boattail, base cavity and base bleed 




Fig. 16 Reduction in drag coefficient by using a combination of boattail, base cavity and base bleed at different flight regime

\section{Conclusion}

Fluent software was used to estimate the best base configuration that would minimize the total drag of a $155 \mathrm{~mm}$ artillery shell. In addition to the basic configuration, six modified configurations were studied These are: boattail only, base blade only, base cavity only, boattail with base bleed, boattail with base cavity and a combination of the three.

It was found that having a boattail with angle 9.5 degrees minimizes the drag coefficient by about $50 \%$ in both subsonic and transonic regimes, and by about $12 \%$ in supersonic regime. While, by using a boattail with angle 15 degrees it was possible to minimize the total drag by $55 \%$ in the case of subsonic regime, and by less than 9.5 degrees in transonic and supersonic regimes. Using base bleed alone (with mass flow rate $\sim 0.037 \mathrm{~kg} / \mathrm{s}$ ) demonstrated a reduction in the drag coefficient of the order of $\sim 50 \%$ at subsonic and transonic regimes, and $\sim 10 \%$ at supersonic regime. The case of using base cavity alone has shown the smallest reduction in the drag coefficient $(\sim 1-2 \%)$.

The higher drag reduction was demonstrated when using a combination of the three effects. For this latter case it was possible to realize a drag coefficient reduction of $\sim 60 \%$ at subsonic regime and $\sim 20-30 \%$.at transonic and supersonic regimes.

\section{References}

[1]. Jubaraj Sohu, "Drag Predictions for Projectiles at Transonic and Supersonic Speeds", June 1986.

[2]. Jayahar S., Richard D. S., Dominic A. T., and Hermann F. F., " Numerical Investigation of Flow Control Mechanisms for Drag Reduction in Supersonic Base-Flows", 44th AIAA Aerospace Sciences Meeting and Exhibit 9-12 January 2006.

[3]. Krieger, R. J. and Vukelich, S. R., "Tactical missile drag, tactical missile aerodynamics", Prog. Astronautics Aeronautics, AIAA 104, 383-420. (1986)

[4]. P. R. Viswanath, "Flow Management Techniques for Base and Afterbody Drag Reduction", Prog Aerospace Sci. Vol. 32. Do. 79-129. 1996. 
[5]. Joseph Kokes, Mark Costello, and Jubaraj Sahu, "Generating an Aerodynamic Model for Projectile Flight Simulation Using Unsteady, Time Accurate Computational Fluid Dynamic Results", ARL-CR-577 September 2006.

[6]. Jubaraj Sahu and Charles J. N., "Three-Dimensional Flow Calculations for a Projectile with Standard and Dome Bases", Journal of Spacecraft and Rockets Vol. 31, No. 1, January-February 1994.

[7]. Masoud Mirzaei Sina Araibi, "Drag optimization for axisymmetric afterbodies with jet plume using computational fluid dynamics", ANZIAM J. 46 (E) pp 2005.

[8]. R H. Korkegi and L. M. Freeman "Aft-Body Drag Reduction by Combined BoatTailing and Base Blowing at M=3", AIAA Journal 1976.

[9]. Design of Aerodynamically Stabilized Free Rockets MIL-HDBK-762(MI) 17 July 1990

[10]. T. Sailaranta1 and A. Siltavuori, "A Simplified Base-Bleed Unit for Artillery Projectiles", $23^{\mathrm{RD}}$ International Symposium on Ballistics Tarragona, Spain 16-20 April 2007.

[11]. Herve Bournot, Eric Daniel, and Roxan Cayzac, "Improvements of the base bleed effect using reactive particles", International Journal of Thermal Sciences 45 (2006) 10521065 January 2006.

[12]. Mauri Tanner, "Base Cavity at Angles of Incidence", AIAA Journal, Vol. 26, NO. 3 1987.

[13]. Paul Weinacht and Jubaraj Sahu, "Navier Stokes predictions of missile aerodynamics" AGARD June 1994

[14] W. P. Wolfe, and W. L. Oberkampf, "Drag Prediction for Projectile and Finned Bodies in Incompressible Flow" Journal of Spacecraft and Rocket Vol. 24 No. 1 JanuaryFebruary 1987.

[15] R. M. Cummings, H. T. Yang and Y. H. Oh, "Supersonic, Turbulent Flow Computation and Drag Optimization for Axisymmetric Afterbodies" Computers \& Fluids Vol. 24, No. 4, pp. 487-507. 1995. 